\title{
STAND-ALONE WIND ENERGY CONVERSION SYSTEM WITH MAXIMUM POWER TRANSFER CONTROL
}

\section{SISTEMA AISLADO DE CONVERSIÓN EÓLICA CON CONTROL DE MÁXIMA TRANSFERENCIA DE POTENCIA}

\author{
Miguel López $^{1} \quad$ Jean-Claude Vannier ${ }^{2}$ \\ Recibido 9 de marzo de 2009, aceptado 11 de septiembre de 2009 \\ Received: March 9, 2009 Accepted: September 11, 2009
}

\begin{abstract}
RESUMEN
Un sistema de generación eólica para una aplicación aislada es presentado en este artículo. Una topología de convertidores electrónicos de potencia elevador y reductor conectados en cascada es propuesta para controlar la producción eólica en todo el rango de velocidades del viento. Para el rango de vientos suaves, la estrategia de control permite seguir el máximo coeficiente de potencia de turbina eólica mediante el ajuste de la velocidad de rotación del generador. En el rango de vientos fuertes, la regulación de la potencia del sistema se hace igualmente por control de la velocidad de giro del generador. La acción de control es realizada mediante el convertidor DC/DC de potencia el cual modifica su tensión de entrada, cambiando así la tensión en los terminales de la máquina y por consecuencia variando la velocidad de rotación del generador. El sistema propuesto es validado mediante simulación por computador. Los resultados muestran que el sistema de control propuesto actúa de buena manera para su aplicación en sistemas autónomos de generación eólica.
\end{abstract}

Palabras clave: Conversión de potencia, energía eólica, control lineal.

\begin{abstract}
A controlled wind generation system for a stand alone application is presented in this paper. A cascaded step-up/step-down power electronic converters topology is proposed to control the wind power system in the whole wind speed range. For the low wind speed range, the control strategy is aimed to follow the wind turbine's maximal power coefficient by adjusting the generator's rotational speed. For high wind speeds, the system power regulation is also made by controlling the generator speed. This control is made by the DC/DC power electronic converter, which modifies its input voltage, changing the machine voltage and consequently varying the generator's rotor speed. The proposed system is validated by computer simulation. The proposed control system shows a good performance for its application in autonomous wind energy systems
\end{abstract}

Keywords: Power conversion, wind energy, linear control.

\section{INTRODUCTION}

Isolated places or locations where the grid is unavailable are one of the main commercial applications of stand-alone wind turbines [1-3]. Autonomous variable speed wind energy systems have been studied in the past decades and they have shown a high efficiency and good performance in face of constant speed or non controlled systems, even in low power range [1-6].

For wind turbines (WT) of less than $50 \mathrm{~kW}$, particularly in the lowest power range, the permanent magnet synchronous generator (PMSG) is mostly chosen because of its low cost, reduced power losses, simple construction and no external magnetization characteristics [7].
Most of switch-mode electronic power converters, from small $\mathrm{DC} / \mathrm{DC}$ choppers to large $\mathrm{AC} / \mathrm{AC}$ threephase converters, are used to obtain an efficient power transfer from the WT rotor to the electrical system. The system's power level defines the appropriate power electronic converter: choppers for battery chargers and low power DC applications [3-4, 6] and voltage or current source inverters for the connection to $\mathrm{AC}$ power systems [8-9].

Electrical machine drives are the optimal complement for classic aerodynamic wind turbine control strategies. The variable speed operation of the electric machine (in indirect grid connection or isolated applications) has shown advantageous for several reasons.

\footnotetext{
1 Escuela de Ingeniería Eléctrica. Pontificia Universidad Católica de Valparaíso. Avda. Brasil 2143. Valparaíso, Chile. E-mail: miguel.lopez@ucv.cl

2 Département d'Electrotechnique et de Systèmes d'Energie. École Supérieure d'Electricité. 3 rue Joliot Curie, Gif-sur-Yvette, France.

E-mail: jean-claude.vannier@supelec.fr
} 
Previously studied power structures and control schemes in low power wind energy systems [3-6] are helpful to propose a new topology.

In this article, a power electronic conversion system with a diode rectifier and a cascaded DC/DC converter is presented and studied for its application in a stand-alone wind energy system. The cascaded DC/DC converter is composed of a boost converter and a buck converter to optimize the wind turbine operation for all its wind speed range.

The proposed topology is well suited for a low power DC system with battery storage. Along with the electrical generator, the principal electric component of the proposed wind energy system is the proposed DC/DC converter. Controllability of the system voltage allows the machine rotational speed adjustment to obtain the maximal wind turbine available power.

A decoupled two-stage control system is designed for proper operation of the wind energy system. The two (boost and buck) converters are controlled independently and operate complementarily. A simple linear control for the system rotation speed gives the voltage reference to a feed-forward control of the cascaded converter.

Results show that the proposed structure can operate with a good performance in a stand-alone wind energy conversion system for low power generation applications.

\section{CONTROL OF LOW POWER WIND ENERGY SYSTEMS}

A typical wind turbine power curve is shown in Figure 1 [1-2]. The wind system starts to generate when wind speed reaches the threshold $v_{\text {cut } i n}$. This threshold is dependent of many factors of the wind energy system. For higher wind speed values, the generated power of the wind turbine rises until rated wind speed $v_{N}$ and rated power $P_{N} . v_{N}$ depends on system design parameters and it is frequently chosen between 11 and $15 \mathrm{~m} / \mathrm{s}$ as most of the wind potential is located under these speeds. For higher wind speeds, the system is regulated at $P_{N}$ until $v_{\text {cut-off }}$ is reached. Then, the wind energy system is automatically put out of production for security reasons.

The most frequent methods to control a wind turbine are: a) blade pitch control, b) passive stall control, c) active stall control and d) yaw control [2].

The well-known wind power equation for wind turbines is

$$
P=\frac{1}{2} \rho \cdot A \cdot C_{P} \cdot v^{3}
$$

From this equation, $\rho$ is the air density, $A$ is the blade sweeping area, $C_{P}$ is the power coefficient, and $v$ is the instantaneous wind speed. When controlling the WT, the power coefficient is useful as it is the only variable and controllable parameter -wind speed is variable but not controllable-. The $C_{P}$ value is dependent of the wind speed and the turbine rotation speed; it has a non linear behavior in terms of the tip-speed ratio $\lambda$ and it is a characteristic of each type of wind turbine. The tip-speed ratio $\lambda$ is an aerodynamic variable of the WT defined on (2), where $\Omega$ is the WT rotor speed and $R$ is the WT rotor radius (blade length). Figure 2 shows the evolution of $C_{P}$ vs. $\lambda$ for different types of wind turbines.

$$
\lambda=\frac{\Omega R}{v}
$$

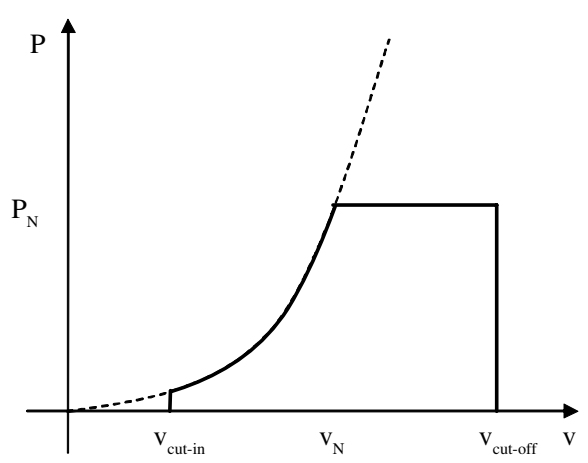

Figure 1. Typical curve of a wind turbine

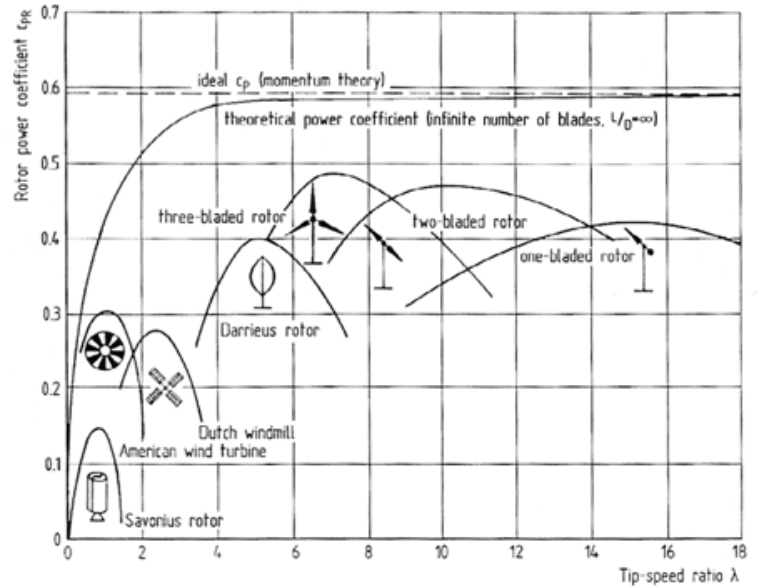

Figure 2. Power coefficient for different wind turbine types [2]. 
From Figure 2, it is observable that a unique optimal point $\left(\lambda^{*}, C_{P}{ }^{*}\right)$ exists for each kind of WT. This is useful for control purposes because by following this optimum, the power coefficient is maximized and, therefore, maximizing the WT power generation also for low speed winds.

The blade pitch control is nowadays the preferred method for large WTs. But for low power WTs, the blade pitch angle adjustment is expensive and it is not justified. Therefore, control for light winds, if there is any, can be done by electric means. The electric system can also regulate the power output for strong winds, but aerodynamic stall control can also be used.

Multiple poles permanent magnets synchronous generators (PMSG) are preferred for the $<20 \mathrm{~kW}$ range for lower costs reasons and gearless operation. However, it is possible to find control structures for wounded synchronous generators [6]. All these low power generation systems have storage means, mainly battery banks; therefore, control is done referred to the DC voltage.

For light winds $\left(v<v_{N}\right)$, control systems are designed to match the maximal power transfer point. This can be done by following the optimal tip-speed ratio, therefore obtaining the maximal $C_{P}$. For strong winds, regulation at $P_{N}$ is needed [1-2]. To such a control scheme, digital programmable systems like fast microcontrollers and digital signal processors are appropriated.

The control variable usually used is the duty cycle of a DC/DC power converter to fit the voltage at the PMSG terminals [3-4] or to control the excitation circuit of the wounded generator [6]. Others use the firing angle of a controlled rectifier [5].

The optimal power to rotation speed relation is largely used to avoid expensive anemometers. A model of the electric system can be done to obtain an optimal relation between the DC voltage and the rotor speed [3]. The rotor speed measurement is done by tachymeter or obtained from the electric frequency.

\section{PROPOSED POWER CIRCUIT}

The proposed conversion system is composed of a small tri-blade horizontal axe wind turbine (HAWT), a mechanical transmission gearbox, a three-phase permanent magnet synchronous generator (PMSG), a three-phase diode bridge, a DC/DC converter and a battery storage system (Figure 3).

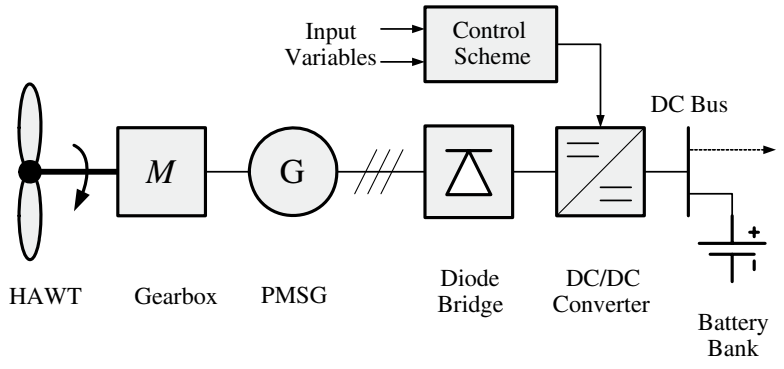

Figure 3. Proposed wind energy conversion system.

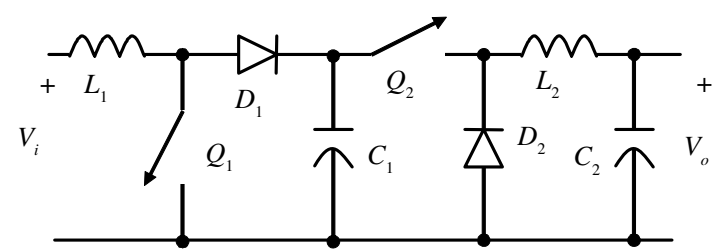

Figure 4. Cascaded (Boost + Buck) DC/DC power converter proposed for the wind energy conversion system.

The HAWT has the higher aerodynamic power coefficient of WTs and its optimal rotor speed is relatively higher than other types (Figure 2). These characteristics make it most efficient and best suited for electric generation applications [1-2]. The gearbox allows meeting the turbine rotor speed with the generator rotor speed. The PMSG is the best suited generator for low power wind energy applications due to its simplicity and low costs. In particular, the PMSG of the proposed scheme can be obtained off-the-shelf; it does not need to be specially designed for this kind of application like other multi-pole schemes previously proposed [3-5].

Similar topologies have been previously proposed, studied and verified; main differences with the proposed structure are the PMSG and the DC/DC converter. A boost converter is used to enhance the power production in the light winds range in [3] and a buck-boost converter is used to control the rotor speed in [4].

The proposed variable speed topology (Figure 4) combines principal advantages of previous approaches: a non chopped waveform in input current and the possibility of step-down and step-up voltage conversion.

The proposed cascaded converter has an input series inductor $L_{1}$; with this element, the input current has a main DC component and a ripple that depends on the converter design. This characteristic allows also the operation has a power factor corrector.

The converter step-up capacity raises the operation range for light winds by reducing the system minimal wind 
and allows following the maximal power transfer point [3-4]. The converter step-down capacity allows a voltage reduction in the generator when wind is higher than rated; this way following the rated power and avoid surcharging the system [4].

The generation system has battery storage. The battery voltage limited to $72 \mathrm{~V}_{\mathrm{DC}}$ for security reasons. The PMSG has a nominal voltage of $60 \mathrm{~V}_{\mathrm{LL}}$. Semiconductors of the cascaded are power MOSFETs and fast recovery diodes for high frequency switching.

The system rotor speed is controlled by the converter voltage control. This way, the generator voltage is adjusted to obtain the desired rotor speed. The proposed speed control follows the tip speed ratio that maximizes the wind turbine power coefficient for light wind speeds and regulates at rated power for strong wind speeds.

\section{PROPOSED CONTROL SCHEME}

The system control strategy is based in two decoupled stages (Master/Slave scheme): The first stage (Master) generates the DC voltage reference to obtain the desired rotor speed in a closed loop control strategy. The second stage (Slave) is the converter control that reaches the desired voltage value using a simple open loop scheme.

\section{Generator's rotor speed control}

It is known that the mechanic power of the WT depends on air density, blade sweeping area, the wind speed and the power coefficient. The air density and the sweeping area can be considered as constant parameters and the wind speed is not controllable. Power coefficient is characteristic of the WT and its value depends on tip speed ratio. We have seen previously that there is an optimal $\lambda$ that maximizes $C_{p}$; therefore; for each wind speed value, there is an optimal rotor speed that maximizes the wind energy conversion system generation. This optimal relation is expressed in equation (3).

$$
P_{i}(\Omega)=P_{t}^{*}=\frac{1}{2} \rho \cdot A \cdot C_{P}^{*} \cdot\left(\frac{R}{\lambda^{*}}\right)^{3} \Omega^{3}
$$

As the PMSG has not field (excitation) control, the goal of the control system is to regulate the machine voltage to adjust the system rotor speed. The voltage control of the generator is done by the DC/DC converter, which modifies its input voltage (diode bridge output voltage) by means of the duty cycle. This way, the variable rotor speed control is done indirectly.

If the wind speed measurement is available, the rotor speed reference is calculated easily by equation (4) [8]. The advantage of this approach is the direct and simple relation. But an accurate wind speed measurement is difficult and requires the use of an expensive anemometer. Another method proposes to follow the maximal power by rotor acceleration in terms of the disequilibrium of the mechanical power and the electrical power [9]. The method does not use the wind speed measurement, but oscillations in the vicinity of the operating point may occur and the tracking of rapid changes can be limited [3]. Others approaches propose a control scheme based on a predefined relation between the generator electric frequency and the output power [4] or between the frequency and the system DC voltage [3]. In these methods, the wind speed measurement is not required either, but electric frequency or the rotor speed and the output power (in one case) or the DC voltage (for the other) must be measured. For the method with DC voltage measurement, models for the generator, the diode bridge and the DC/DC converter have to be included in the control system. In general, control schemes need a rotor speed (or electric frequency) measurement for closed loop control purposes.

$$
\lambda^{*}=\frac{R \cdot \Omega^{*}}{v} \Rightarrow \Omega^{*}=\frac{\lambda^{*}}{R} v
$$

Once the output power measurement is known, the rotor speed reference $\Omega^{*}$ can be obtained also from (5):

$$
\Omega^{*}=\frac{\lambda^{*}}{R}\left(\frac{2 P}{\rho \cdot A \cdot C_{P}^{*}}\right)^{1 / 3}
$$

For simplicity reasons, equation (4) is used in this work to validate the proposed power scheme. For this, the WT blade radius $R$, and the optimal tip speed ratio $\lambda^{*}$ must be known.

The system rotor speed is controlled by a PI compensator and the output control signal is the voltage reference to the cascaded converter control. Figure 5 shows the proposed speed control system scheme.

A feed-forward speed control bloc is added to the linear compensator to help the control task. Equation (6.5) is the function of this bloc. It takes in account the effect of calculating an approximation of the generator voltage which takes the system rotor speed to the reference value (6). 


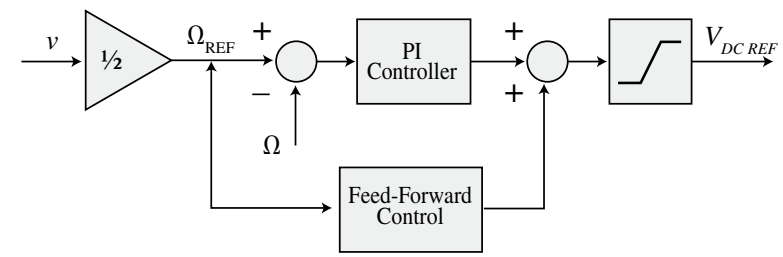

Figure 5. Bloc diagram of the proposed speed control system.

$$
\begin{gathered}
U_{D C}^{*}=G \cdot u_{s}^{*} \\
e=\omega \cdot \psi_{r}=p \cdot \Omega_{G} \cdot \psi_{r} \\
\omega=p \cdot \Omega_{G} \\
u_{s}^{*} \approx e \\
\Rightarrow U_{D C}^{*} \approx G \cdot p \cdot \Omega_{G}^{*} \cdot \psi_{r}
\end{gathered}
$$

$G$ is the diode bridge AC to DC voltage gain. $e$ is the generator electromotive force (emf) amplitude in sinusoidal steady state, $p$ is the generator pairs of poles number and $\Psi_{r}$ is the flux of the generator magnets. The approximation neglects the generator series impedance; so voltages $e$ and $u_{s}$ are almost equal (6.4). The error made by this approximation is minimized by the integral action of the PI speed controller.

A saturation bloc is added to maintain the system rotor speed within its rated value.

\section{Cascaded converter control strategy}

The proposed cascaded power converter is composed of an input boost converter plus an output buck converter. Each power converter is controlled in an independent and complementary way. To control the DC voltage, a feed-forward strategy is used.

A selector allows the converters complementary operation. For this, the DC voltage measurement at the boost converter input (diode bridge output voltage) is used. This voltage is proportional to the $\mathrm{AC}$ voltage at generator terminals, which is approximately proportional to the system rotor speed.

To control the $\mathrm{DC}$ voltage, relations between $\mathrm{DC}$ voltages (diode bridge DC voltage $V_{D C}$ and output battery voltage $V_{\text {Batt }}$ ) are considered (7).

$$
V_{\text {Batt }}=A_{v} \cdot V_{D C}=f(D) \cdot V_{D C}
$$

The voltage gain $A_{v}$ of buck and boost converters for continuous current mode are defined by (8) and (9) respectively.

$$
\begin{gathered}
A_{v \text { Buck }}=\frac{V_{o}}{V_{i}}=D \\
A_{v \text { Boost }}=\frac{V_{o}}{V_{i}}=\frac{1}{1-D}
\end{gathered}
$$

So, as the battery voltage -which is the wind energy system output voltage- remains nearly constant and when boost converter is on stand-by mode (switch open, diode in forward mode), the control variable when buck converter is regulating is (10). The voltage reference value $V_{D C R E F}$ is obtained from generator speed control.

$$
D_{\text {Buck }}=\frac{V_{\text {Batt }}}{V_{D C \text { REF }}}
$$

When boost converter is controlling the DC voltage for maximal power output, the buck converter is now in stand-by mode (switch closed, diode in blocking state), the steady state value of the control variable for the stepup converter is (11)

$$
D_{\text {Boost }}=1-\frac{V_{D C R E F}}{V_{\text {Batt }}}
$$

Figure 6 shows the proposed open loop control scheme for the cascaded DC converter, based on a pulse width modulation (PWM) scheme, where the duty cycle for each converter is calculated and converted into gate signals. The DC voltage reference is compared to battery voltage to define which converter will operate and a simple digital circuit completes the task.

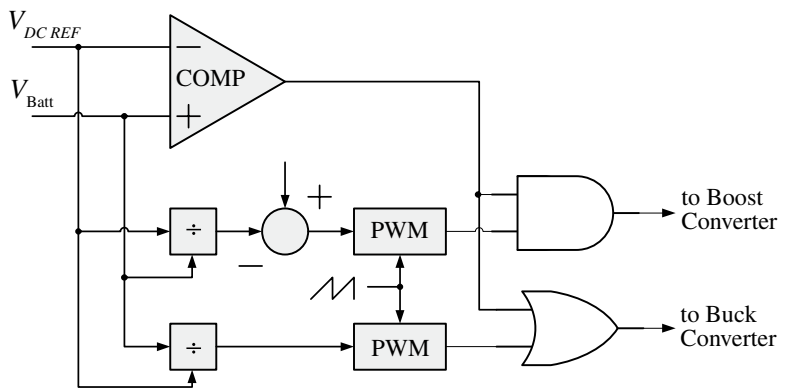

Figure 6. Bloc diagram of the proposed open loop control for the cascaded converter 
The AND function is used to control the boost converter because it operates as DC/DC converter only when DC voltage reference is lower than battery voltage. The power transistor must remain open elsewhere.

The OR logic function allows controlling the buck converter when required DC voltage is higher than battery voltage. The power transistor must remain closed when the boost converter operates.

\section{RESULTS}

The wind energy conversion system is validated by computer simulation, using Matlab PowerSym toolbox.

The WT model is obtained from equation (1) and from an approximation of the $C_{P}$ curve in terms of the tip speed ratio $(\lambda)$. Therefore, input signals for the WT model are the wind speed and system rotor speed. The gearbox was modeled as a gain for simplicity reasons.

The PMSG was chosen from the PowerSym preset generators list.

With the goal of a correct observation and analysis of the proposed power and control systems behavior, the wind was supposed as a known and controllable parameter.

The proposed wind energy conversion system was verified by simulation for a stand alone application. System parameters are shown in Table 1.

Results of the rotor speed control are shown in Figures 7 and 8. Figure 7 shows the rotor speed behavior for successive raising steps of wind speed $(3 \mathrm{~m} / \mathrm{s}$ to $4 \mathrm{~m} / \mathrm{s}$ then $5 \mathrm{~m} / \mathrm{s}$ ). Figure 8 shows the down steps. Electric variables are shown for the same cases in Figures 9 and 10.

From Figures 7 and 8 it can be observed that the proposed control system (decoupled linear speed control plus feedforward converters control) can follow correctly the speed reference. A less than 20\% overstep is observed when the wind speed step rises; nevertheless, when the wind speed step goes down, the obtained overstep is much higher, near $50 \%$. Some small oscillations are observed in steady state also. These effects can be corrected by adjusting the controller parameters and can be explained by non linear and high frequency dynamics that are neglected by the control system.
Table 1. Parameters of the wind energy conversion system.

\begin{tabular}{|l|l|}
\hline \multicolumn{1}{|c|}{ Parameter } & \multicolumn{1}{c|}{ Value } \\
\hline WT blade radius & $R=1.8 \mathrm{~m}$ \\
\hline WT optimal tip speed ratio & $\lambda^{*}=6.8$ \\
\hline Resistance, inductance, magnets flux & $R_{s}=0.9585 \Omega \geq$, \\
and poles pairs of the PMSG & $\begin{array}{l}L_{s}=5 \mathrm{mH}, \\
\Psi_{r}=0.1827 \mathrm{~Wb}, \\
p=4\end{array}$ \\
\hline Gearbox transformation ratio & $M=30 / 7$ \\
\hline Boost converter components & $L=5 \mathrm{mH}, C=6 \mu \mathrm{F}$ \\
\hline Buck converter components & $L=6 \mathrm{mH}, C=33 \mu \mathrm{F}$ \\
\hline Battery Voltage & $V_{\text {Batt }}=72 \mathrm{~V}$ \\
\hline Rotor speed PI controller & $K_{P}=0.2, \tau_{I}=1 / 100$ \\
\hline
\end{tabular}

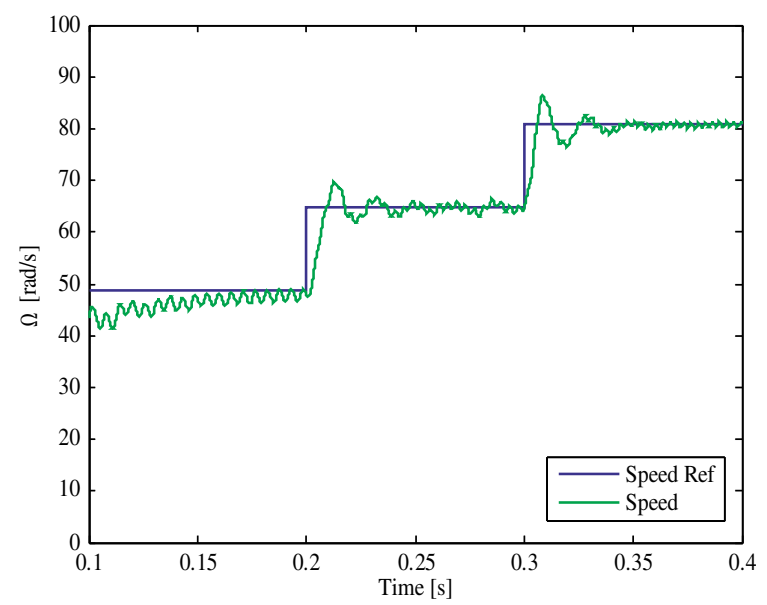

Figure 7. Simulation results for step changes in wind speed from 3 to 4 and 4 to $5 \mathrm{~m} / \mathrm{s}$. System rotor speed (reference and actual values).

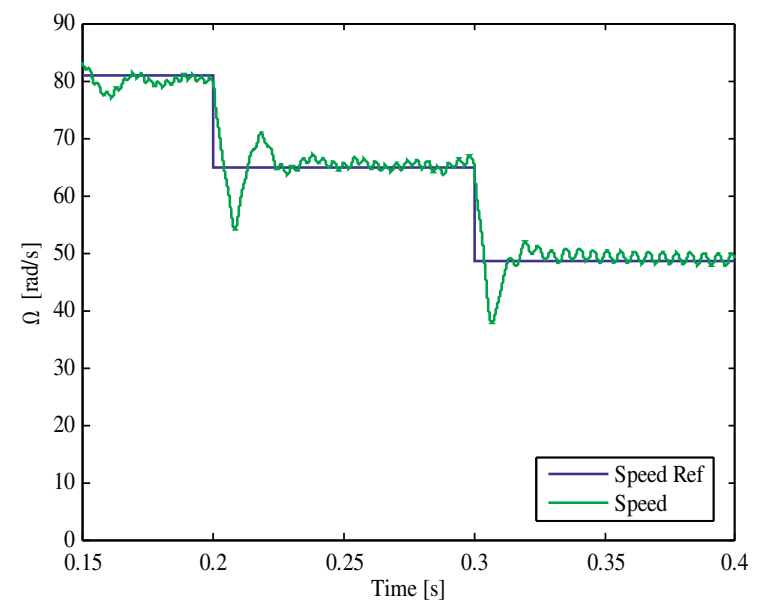

Figure 8. Simulation results for step changes in wind speed from 5 to 4 and 4 to $3 \mathrm{~m} / \mathrm{s}$. System rotor speed (reference and actual values). 

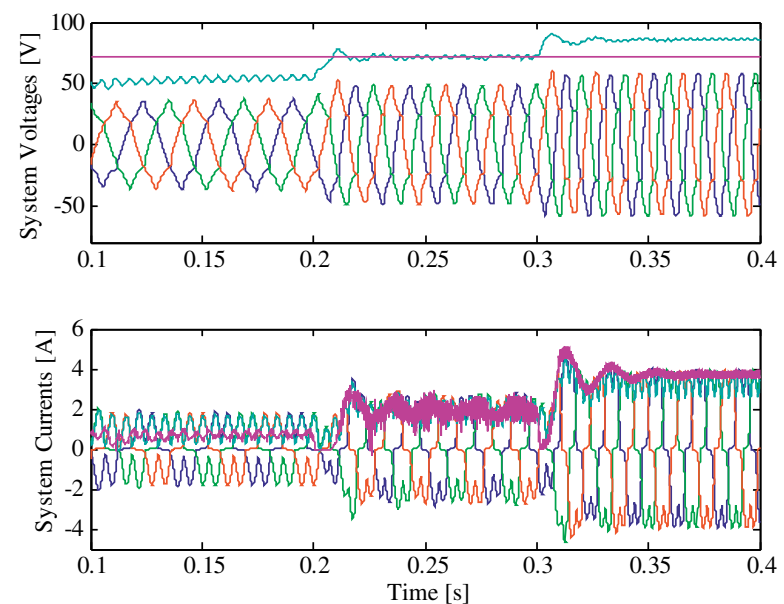

Figure 9. Simulation results for the proposed structure for step changes in wind speed from 3 to 4 and 4 to $5 \mathrm{~m} / \mathrm{s}$. AC voltages and currents.
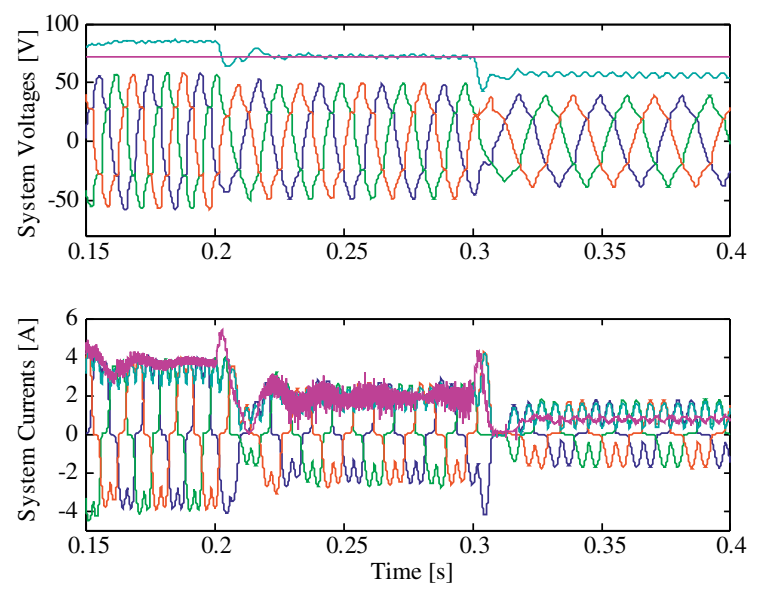

Figure 10. Simulation results for the proposed structure for step changes in wind speed from 5 to 4 and 4 to $3 \mathrm{~m} / \mathrm{s}$. AC voltages and currents.

From Figures 9 and 10, the control action can be observed in system voltages and currents. The proposed scheme can the control DC voltage to modify the generator speed, this is verified in AC voltages and currents frequency.

Some oscillations of the controlled DC voltage are observable; these are more evident for low voltages.

A boundary zone is observed, when wind speed is $4 \mathrm{~m} / \mathrm{s}$. In this zone the current is not controlled properly. This effect is due to a reference voltage almost equal to the battery voltage. Both converters are almost out of range: duty-cycle of boost converter near to 1 and buck converter near to 0 and the system bounces between both converters. In the normal operating ranges of power converters, current remains correctly regulated. Some oscillations are present when wind speed is $3 \mathrm{~m} / \mathrm{s}$, which can be explained by a small reactive elements resonance in the power circuit or by the output ripple current of the diode rectifier. In the normal operating ranges of power converters, current remains properly regulated.

\section{CONCLUSIONS}

An electronic power conversion system composed of a diode bridge rectifier and a cascade DC/DC converter is presented and studied for its application in a stand alone wind generation system. The proposed system is validated by computer simulation. The combination of a generator's speed feed-back control with an open-loop feed-forward converter's voltage control has shown a good performance for the autonomous wind energy system.

\section{ACKNOWLEGMENT}

The authors would like to thank the Chilean Government and the Ecole Supérieure d'Electricité (Supelec) for their economical support in this research. M. Miguel Lopez was a "Presidente de la República de Chile" scholarship holder during his doctoral studies.

\section{REFERENCES}

[1] S. Mathew. "Wind Energy: Fundamentals: Resource Analysis and Economics". Springer, $1^{\text {st }}$ Ed. Germany. 2006.

[2] E. Hau. "Wind Turbines: Fundamentals, Technologies, Application, Economics". Springer. Germany. 2006.

[3] A.M. Knight and G.E. Peters. "Simple Wind Energy Controller for an Expanded Operating Range". IEEE Trans. on Energy Conversion. Vol. $20 \mathrm{~N}^{\circ} 2$, pp. 459-466. 2005.

[4] A.M. De Broe, S. Drouillet and V. Gevorgian. "A Peak Power Tracker for Small Wind Turbines in Battery Charging Applications". IEEE Trans. on Energy Conversion. Vol. 14 N $^{\circ}$ 4, pp. 1630-1635. 1999.

[5] B.S. Borowy and Z.M. Salameh. "Dynamic Response of a Stand-Alone Wind Conversion System with Battery Energy Storage to a Wind 
Gust". IEEE Trans. on Energy Conversion. Vol. 12 $\mathrm{N}^{\circ}$ 1, pp. 73-78. 1997.

[6] M. Ermis, H.B. Ertan, E. Akpinar and F. Ulgut. "Autonomous Wind Energy Conversion System With a Simple Controller for Maximum-Power Transfer". IEE Proceedings-B. Vol. 139 N $^{\circ}$ 5, pp. 421-428. 1992.

[7] L. Söderlund and J.T. Eriksson. "A PermanentMagnet Generator for Wind Power Applications". IEEE Trans. on Magnetics, Vol. 32 N $^{\circ}$ 4, pp. 23892392. 1996.

[8] S.A. Papathanassiou and M.P. Papadopoulos. "Dynamic Behavior of Variable Speed Wind
Turbine under Stochastic Wind". IEEE Trans. on Energy Conversion. Vol. 14 No 4, pp. 1617-1623. 1999.

[9] A.S. Neris, N.A. Vovos and G.B. Giannakopoulos. "A Variable Speed Wind Energy Conversion Scheme for Connection to Weak AC Systems". IEEE Trans. on Energy Conversion. Vol. 14 N$^{\circ}$ 1, pp. 122-127. 1999.

[10] M. López and J.C. Vannier. "Stand-Alone Wind Energy Conversion System with Maximum Power Transfer Control". Proc. of the XVIII Congreso de la Asociación Chilena de Control Automático. Santiago, Chile. 2008. 